\title{
A Three-Equation Thermocline Thermal Energy Storage Model for Bidisperse Packed Beds
}

\author{
Christian Odenthal $^{1}$, Freerk Klasing ${ }^{1}$ and Thomas Bauer ${ }^{1}$
}

${ }^{I}$ German Aerospace Center (DLR), Institute of Engineering Thermodynamics, Linder Höhe, 51147 Köln

\section{Abstract}

The present publication introduces a novel three-equation model for the simulation of bidisperse packed beds, typically utilized in thermocline thermal energy storages with filler. These systems aim for the substitution of a large fraction of cost intensive liquid storage material such as molten salts by a cost effective solid storage material. A higher packing density can be achieved by a combination of large and small particles, i.e. a bidisperse packing. For the simulation of such systems, the currently most widely applied Schumann and continuous solid phase models consider the solid phase as single sized spheres with a mean particle diameter derived from the bidisperse packing. The present work introduces a novel approach, where, besides the differential equation for the fluid, two differential equations for the small and for the large particles are applied. The model is validated with bidisperse experimental data from the literature. For comparison a reference case of a $100 \mathrm{MW}$ electric solar thermal power plant is defined and the bidisperse model is compared to the Schumann model in its outcome for four different particle size combinations. In the single blow operation, where the storage volume is charged from uniform temperature, the temperature curves show differences of up to 6.6 Kelvin. If the thermocline is given time to develop over several consecutive cycles, the difference in charging and discharging time of one period reaches up to $3.5 \%$. With the model presented in this work, accuracy of long duration or annual simulations can be significantly increased.

\section{Introduction}

\subsection{Molten salt thermal energy storage and its applications}

With increasing share of intermittent renewable energy sources, energy storage is playing an important role in further enhancing the penetration of renewables in power grids. For concentrating solar power (CSP) plants, two-tank molten salt thermal energy storage (TES) is currently the state-of-the-art for large scale energy storage (Gil et al., 2010; González-Roubaud et al., 2017). In this concept, molten salt is extracted from the cold storage tank, heated to a higher temperature level through concentrated solar irradiation and subsequently stored in the hot storage tank. During night times or cloudy weather conditions, hot molten salt is extracted, used for steam production and then fed back to the cold tank. Besides CSP applications, a new field of application is considered in Germany by combining thermal energy storage with conventional power plants (Olaf Winter, 2019).

A novel approach for the molten salt storage concept is the application of only a single storage tank for storing both hot and cold molten salt simultaneously. Both fluid phases are separated through natural stratification. The cold salt is extracted from the tank at the bottom and the hot salt is at the top of the tank. For CSP plants, almost exclusively a mixture of $60 \mathrm{wt} \%$ Sodium Nitrate and $40 \mathrm{wt} \%$ Potassium Nitrate (called Solar Salt) is utilized. Typical costs for Solar Salt are reported in the range of 400$900 \$ /$, which makes up roughly $50 \%$ of the total costs of the storage system (Herrmann et al., 2004). If a significant fraction of the molten salt can be substituted by a packed bed of a cost effective solid storage material, the total costs can be vastly reduced. With typical costs of natural basalt rocks of only around $50 \$ / t$ and the molten salt making up $50 \%$ of total costs, it becomes evident that substituting as much as possible molten salt with basalt rocks is the key for significant cost reductions. Reduction of 
void volume can only be achieved by multidisperse packings of particles having a significant difference in size, as illustrated by Fig. 1. A typical packing of rocks has a void fraction of $50 \%$, thus substituting the same amount of molten salt. If this void is filled with smaller rocks, having $50 \%$ void themselves, the void can be further reduced to $25 \%$. From Fig. 1 can also be deduced that the smaller rocks must be significantly smaller than the larger ones, to fit into the gaps. Fundamental theory of packed beds with different particle sizes can be found elsewhere (Rhodes, 2008).

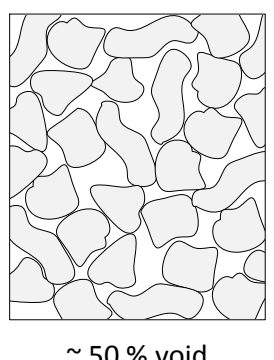

$50 \%$ void

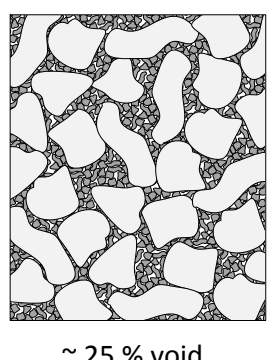

$\sim 25 \%$ void

Fig. 1: Illustration of void reduction from single size packed bed (left) to bidisperse packings (right)

\subsection{Experimental work with thermocline high temperature thermal energy storage}

In practice, the thermocline concept with filler has been investigated by some authors so far. It has been demonstrated in the 1980 s in a large scale of $170 \mathrm{MWh}_{\mathrm{th}}$ at the SolarOne power plant (Faas et al., 1986). This system used thermal oil as HTF and a rock/sand mixture as filler material. To our knowledge, the only available information about the filler material is the void fraction of $22 \%$ and the larger particle diameter of $4.6 \mathrm{~mm}$.

Experimental results with molten salt, but in a smaller scale of $2.3 \mathrm{MWh}_{\text {th }}$ at temperatures of up to $500{ }^{\circ} \mathrm{C}$ have been presented by Sandia (Pacheco et al., 2002). In this test facility a ternary molten salt mixture $\left(44 \%_{\mathrm{wt}} \mathrm{Ca}\left(\mathrm{NO}_{3}\right)_{2}, 12 \%_{\mathrm{wt}} \mathrm{NaNO}_{3}, 44 \%_{\mathrm{wt}} \mathrm{KNO}_{3}\right.$, similar to Hitec $\left.\mathrm{XL}\right)$ has been used alongside a filler material mixed from 2 parts quartzite rocks and 1 part silica sand. The larger quartzite rocks were reported having $19.05 \mathrm{~mm}$ mean dimeter and the sand with $2.38 \mathrm{~mm}$. The reported void fraction was $22 \%$.

A mid-sized experiment with $3 \mathrm{~m}$ height, $1 \mathrm{~m}$ diameter and thermal oil operating at up to $350{ }^{\circ} \mathrm{C}$ has been investigated at CEA (Bruch et al., 2014). The filler was reported to be a mixture of $20 \%$ sand with $3 \mathrm{~mm}$ mean diameter and $80 \%$ gravel having $30 \mathrm{~mm}$ mean diameter. The reported overall void fraction achieved was $27 \%$. CEA has also successfully demonstrated a complete CSP pilot plant, consisting of a Fresnel collector, an Organic Rankine Cycle (ORC) and a thermocline thermal storage with $30 \mathrm{~m}^{3}$ in volume (Rodat et al., 2018, 2015).

Another mid-sized experiment, similar to that of CEA, was developed at the PROMES CNRS Laboratory in Odeillo, a thermocline tank with filler has been integrated to a parabolic trough loop with an ORC. The tank is $3 \mathrm{~m}$ in height and $1.3 \mathrm{~m}$ in diameter $\left(4 \mathrm{~m}^{3}\right)$ (Fasquelle et al., 2017; Hoffmann et al., 2017). The filler material was monodisperse quartzite rock with $41 \%$ void fraction and $40 \mathrm{~mm}$ mean particle diameter. Finally, at DLR a test facility for thermal energy storage in molten salts (TESIS) has been commissioned. The facility has a volume of $22 \mathrm{~m}^{3}$ and is shown in Fig. 3.Currently, experiments with a monodisperse basalt filler packing of 8 to $11 \mathrm{~mm}$ and Solar Salt are carried out (Odenthal et al., 2019). 


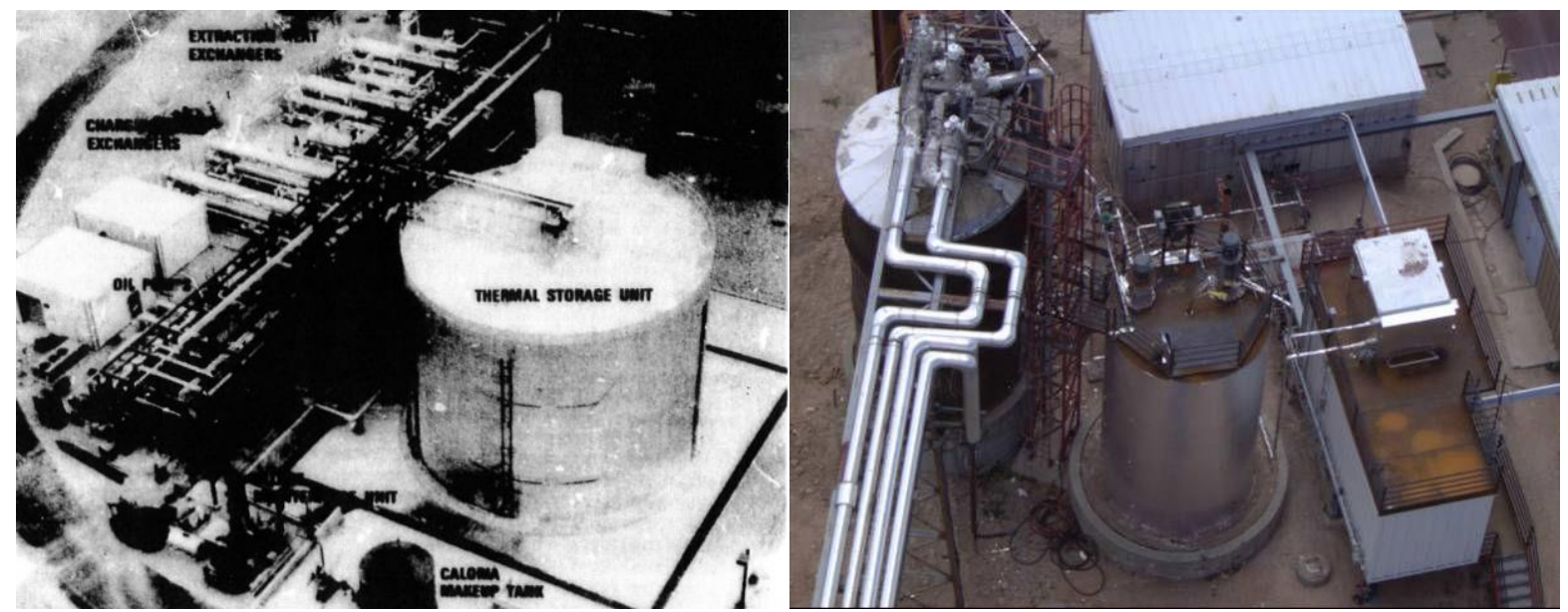

Fig. 2: Thermal oil thermocline storage tank of the SolarOne plant (Faas et al., 1986) (left); Molten salt thermal storage tank test facility at Sandia (Brosseau et al., 2005) (right)

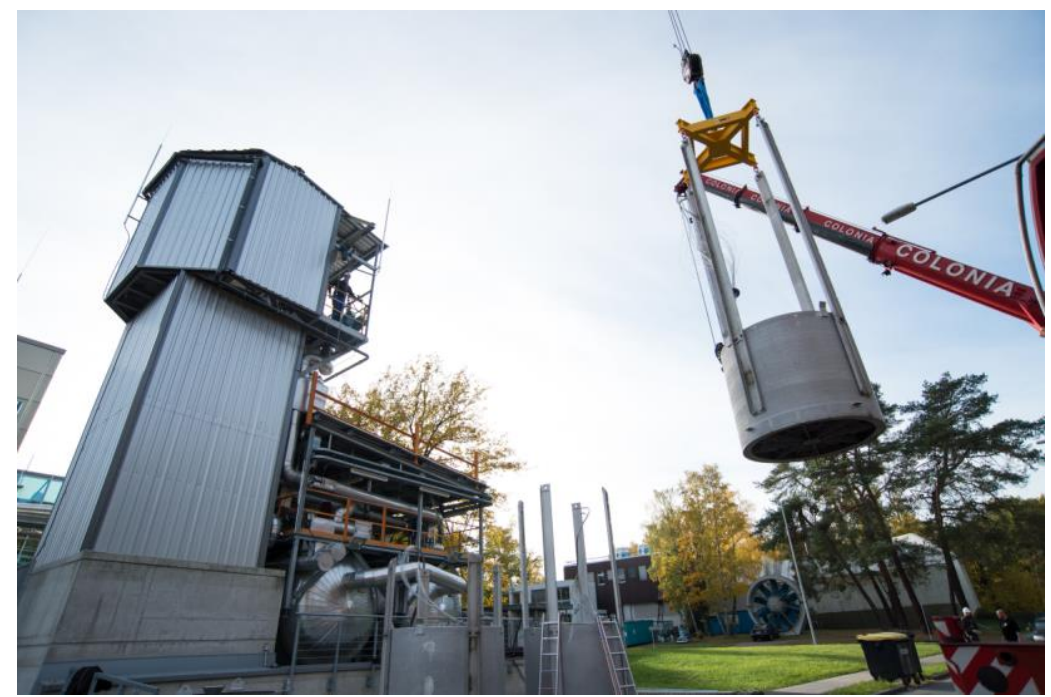

Fig. 3: TESIS test facility during the insertion of three baskets with basalt filler material

\subsection{Literature review of numerical models for thermocline thermal energy storage}

Besides experimental work, numerous publications deal with the simulation of aforementioned systems. (Schmidt and Willmott, 1981; Willmott, 2002) provide a thorough collection of modelling approaches. Both books describe single and multiple-equation modelling approaches. Another comprehensive and well-known work is that of (Ismail and Stuginsky Jr, 1999). The authors present several models suitable for regenerator type storage systems and undertake a parametric study for a comparison. The following sections give a brief overview of one-dimensional models and examples of applications found in the literature.

\section{Single phase model}

The single phase model assumes infinitely high heat transfer between solid and fluid and thus a common temperature of both phases. This allows considering both phases as a homogeneous mixture with only a single differential equation. An effective conductivity of the fluid/solid mixture is considered in this model. This model is used by some authors, for example by (Hoffmann et al., 2016), where three sets of experimental data are compared to the model or by (Bayón and Rojas, 2013) where it is used to derive dimensionless parameters for tank performance prediction and evaluation.

\section{$\underline{\text { Schumann and continuous solid phase model }}$}

The continuous solid phase model uses two coupled partial differential equations for the solid and fluid. A uniform temperature for the solid and a different uniform temperature for the fluid are assumed. Heat transfer between both phases is calculated often from a lumped heat transfer 
correlation, considering additional resistance through conduction inside the solid particles. The continuous solid phase model considers effective thermal conductivity $\lambda_{\mathrm{eff}, \mathrm{x}}$ of the solid/fluid mixture. Without effective thermal conductivity, the model is referred to as the Schumann model (Schumann, 1929).

Some authors using the Schumann model are (Van Lew et al., 2009) who did investigations based on purely non-dimensional calculations. The model is later used by (Li et al., 2011) and (Reddy et al., 2017) for further investigations. (Valmiki et al., 2012) also use the Schumann model which is validated with data of an experiment with rapeseed oil.

The continuous solid phase (CS) model is used by most authors. (Hoffmann et al., 2016) use this model alongside their single phase model for a comparison. (Flueckiger et al., 2014) use their model for system level simulations. (Yang et al., 2012) investigate specific performance criteria for a fictive storage material. (Niedermeier et al., 2018) compare the performance of a molten salt packed bed to a sodium packed bed. Several others utilize a 2D CS model which can be found in a recent review article by (Esence et al., 2017).

\section{Dispersion concentric}

A more sophisticated approach is the utilization of a dispersion concentric model. This model assumes a temperature gradient inside the particles which are also spatially discretized at each fluid node. This is usually justified for high Biot numbers, when the particles are large or heat transfer is very high. Some authors using the dispersion concentric model are (Zhao et al., 2017), (Galione et al., 2015) and (Niedermeier et al., 2018).

All existing models can be extended by considering additional effects. These are temperature dependent fluid properties, heat losses to the environment, either by an overall heat loss coefficient or an additional partial differential equation for the tank walls. Furthermore, much work on correlations for heat transfer coefficients and effective conductivity can be found, as summarized by (Esence et al., 2017). Independently of the numerical model, these correlations can consider numerous other physical effects, such as particle to particle thermal resistance, turbulent mixing or radiative effects, to name a few.

\subsection{Scope and method of the presented paper}

For the practical application of molten salt thermocline TES, the necessity for bidisperse packings has been elucidated, which is also supported by the fact that most experiments actually utilize bidisperse packings. Bidisperse packings are also relevant for particle based heat exchangers, where such bidisperse model could be relevant as well. However, the assumptions made for this publication are intended for molten salts and thus not necessarily valid for other applications.

From the literature survey can be concluded, that a large variety of modelling approaches exists so far. Several authors present very detailed models such as the concentric dispersion models or sophisticated correlations for effects such as effective conductivity. However, all publications known to the authors where bidisperse packings are simulated use the compromise of calculating a mean particle diameter and treating the packing as monodisperse. The purpose of the present work is to introduce a bidisperse model, based on the Schumann model, which is extended by another partial differential equation for the solid phase in order to model the small and large particles separately. In this way, the different heat transfer areas of small and larger particles are addressed.

For reference, the bidisperse model's performance is compared to aforementioned classic Schumann model, where only a mean particle diameter is used. The reason for using the Schumann model as reference is that it is simple and neglects effective conductivity. Radiative heat transfer is also neglected, further simplifying the heat transfer correlation between solid and fluid. Thus, the only difference between both models will be the consideration of the second PDE in the solid phase, which allows focusing on its impact on the model outcome. Neglecting effective conductivity at non-stagnant flow conditions and radiative heat transfer alongside molten salt is also justified from the physical perspective, since both contributions are small compared to the convective heat transfer (Kays et al., 2009; Kunii and Smith, 1960). 
Both models are initially validated by experimental data found in the literature. For the comparison of the two models, simulations for both single blow and cyclic operation are carried out. The single blow operation is causing harsh temperature gradients, since the storage is charged from an initial uniform temperature. The cyclic operation allows investigating slowly developing differences over longer time period. The boundary conditions of the simulations are derived from a practical case. Simulations are run with different packings where the size between large and small particles is varied. Finally, the results are utilized to give recommendations and estimate errors of annual performance calculation of a CSP plant using the single particle and bidisperse models.

\section{Description of the bidisperse model}

The formulation of the model contains several basic assumptions, which are discussed in the following sections.

\subsection{Geometric definitions}

For simulations, the storage volume is considered as a cylindrical container, as shown in Fig. 4. The dimensions are defined by the length $L$ and the diameter $D$ of the storage volume. From these variables, the cross sectional area $A_{0}$ can be calculated.

Due to their natural origin, the filler particles are of irregular shape. For the simulation, it is assumed that the particles are spheres, having the same mean volume $V_{\mathrm{p}}$ as the particles. With this assumption, the diameter $d_{\mathrm{p}}$ of the spheres is defined. As stated beforehand, for liquid thermocline TES typically two differently sized particles $d_{\mathrm{p} 1}$ and $d_{\mathrm{p} 2}$ exist, where $d_{\mathrm{p} 1}$ are the larger particles, as also illustrated in Fig. 4. The Schuman model considers the particle diameter as an average diameter, which can be calculated from

$$
d_{\mathrm{p}}=w \cdot d_{\mathrm{p} 1}+(1-w) \cdot d_{\mathrm{p} 2}
$$

Here, the share in volume of the large filler is denoted by $w$.

The void fraction, i.e. the space not occupied by the filler material is described by the variable $\varepsilon$. Generally, the fluid is referred to by the subscript $\mathrm{f}$ and the solid filler material by the subscript $\mathrm{s}$.

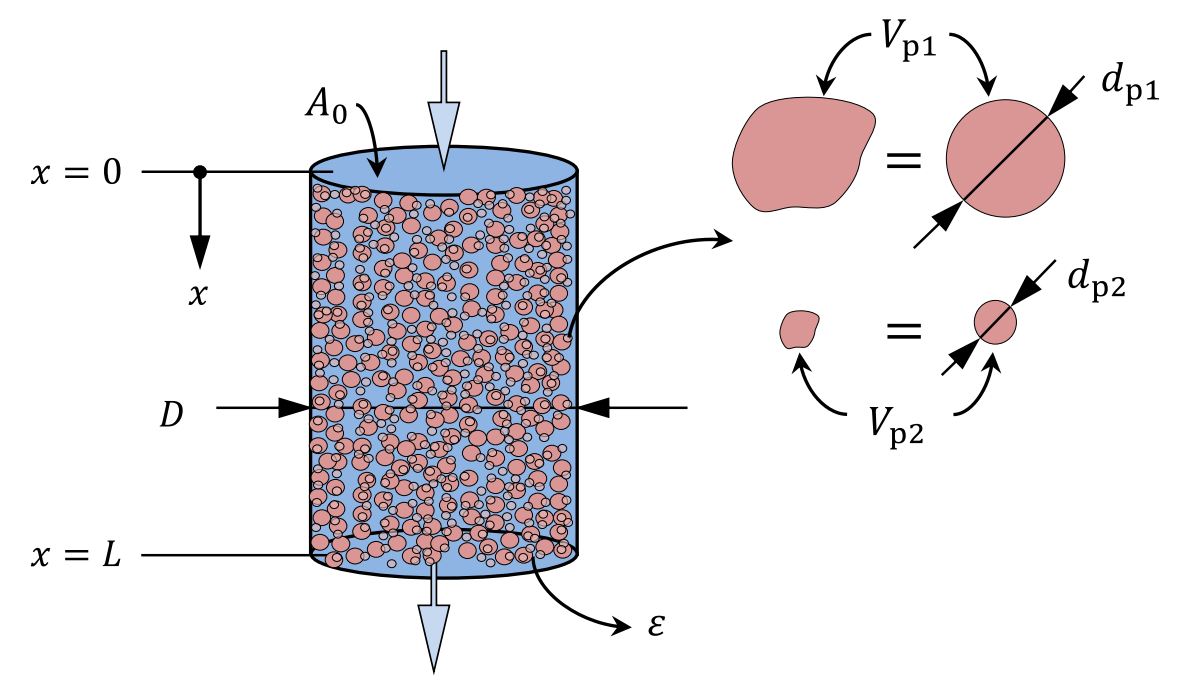

Fig. 4: Geometric properties of the storage volume and the filler particles inside

With these definitions, the models can be described as followed in the next sections. 


\subsection{Modelling approach}

\section{General approach and simplifications}

The thermodynamic model is based on the first law of thermodynamics

$$
\mathrm{d} \dot{Q}+\mathrm{d} P=\mathrm{d} \dot{U}+\mathrm{d} E_{\mathrm{a}} .
$$

No work is added or subtracted $(\mathrm{d} P=0)$ and changes in potential and kinetic energy are negligible $\left(\mathrm{d} E_{\mathrm{a}}=0\right)$. Only heat $(\mathrm{d} \dot{Q})$ is exchanged and inner energy is varying with respect to time $(\mathrm{d} \dot{U})$. The resulting equation is applied to each phase of a volumetric element of the storage volume, where a phase could be the fluid or storage material. Generally speaking, this means that the change in inner energy $u$ equals added and subtracted inner energy through conduction and/or convection as well as thermal power $\dot{Q}^{\prime \prime \prime}$ through heat sinks and sources, as expressed by:

$$
\frac{\partial(\rho u)}{\partial t}+\nabla[u \rho \vec{v}-\lambda \nabla T]=\dot{Q}^{\prime \prime \prime},
$$

where $\rho$ denotes the density, $\vec{v}$ the velocity, $\lambda$ thermal conductivity and $T$ is the temperature. Expressing above equation in a one-dimensional coordinate system with the coordinate $x$ and the static enthalpy $h=u+p / \rho$, the equation now reads:

$$
\frac{\partial(\rho h)}{\partial t}-\frac{\partial p}{\partial t}=-\frac{\partial}{\partial x}\left[h \rho v_{x}-p v_{x}-\lambda_{i} \frac{\partial T}{\partial x}\right]+\dot{Q}^{\prime \prime \prime}
$$

For equation (4), the following assumptions are made:

1. The fluid phase is incompressible, which leads to $\frac{\partial p}{\partial t}=0$ and $\frac{\partial p}{\partial z}=0$. This means that specific inner energy equals specific enthalpy $(\mathrm{d} u=\mathrm{d} h)$.

2. Ideal gas is assumed, therefore $\mathrm{d} h=c_{p, \mathrm{f}} \mathrm{d} T$.

3. Plug flow is assumed with no lateral components, $v_{\mathrm{x}} \neq f(r)$

4. No chemical reactions

5. Homogenous distribution of solid phases, thermophysical properties are not depending on spatial position.

6. Effective bed conduction is neglected, although most authors are considering it when using the continuous solid phase model. According to (Kays et al., 2009), this assumption is justified if for the bulk flow $P e \gg 100$, which can be confirmed. Thus, $\lambda_{i}=0$.

7. We assume constant thermophysical properties.

8. All heat losses to the environment are neglected

With above assumptions and simplifications, the basic differential equation for the models is given by equation (5):

$$
\rho c_{p} \frac{\partial T}{\partial t}=-\rho c_{p} v_{x} \frac{\partial T}{\partial x}+\dot{Q}^{\prime \prime \prime}
$$

This basic differential equation is applied to all phases with further assumptions and simplifications.

\section{Deriving the models from the basic equations}

The bidisperse model uses two partial differential equations for the solid particles. The equations are referred to by the subscripts (s1) and (s2), as illustrated in Fig. 5. The equation for the fluid is given by equation (6) and also illustrated in Fig. 5. The transient term of the fluid contains the void fraction $\varepsilon$ and volumetric heat capacity $\rho_{\mathrm{f}} c_{\mathrm{p}, \mathrm{f}}$. In the convective term, $v_{0, \mathrm{x}, \mathrm{f}}$ denotes the free flow velocity of the fluid. Equation (6) also has two source terms, $\dot{Q}_{\mathrm{f}-\mathrm{s} 1}^{\prime \prime \prime}$ and $\dot{Q}_{\mathrm{f}-\mathrm{s} 2}^{\prime \prime \prime}$, coupling the fluid with each of the two solid phases.

$$
\varepsilon \rho_{\mathrm{f}} c_{\mathrm{p}, \mathrm{f}} \frac{\partial T_{\mathrm{f}}}{\partial t}=-\rho_{\mathrm{f}} c_{\mathrm{p}, \mathrm{f}} v_{0, \mathrm{x}, \mathrm{f}} \frac{\partial T_{\mathrm{f}}}{\partial x}+\dot{Q}_{\mathrm{f}-\mathrm{s} 1}^{\prime \prime \prime}+\dot{Q}_{\mathrm{f}-\mathrm{s} 2}^{\prime \prime \prime} .
$$


For the solid phases, the two equations are given by (7), containing the volumetric heat capacity of the solid $\rho_{\mathrm{s} 1} c_{\mathrm{s} 1}$ and $\rho_{\mathrm{s} 2} c_{\mathrm{s} 2}$, respectively, and no convective terms. A weighting factor $\mathrm{w}=0 . .1$ is introduced, which describes the ratio between the two solid phases as also used in equation (1).

$$
\begin{aligned}
& w \cdot(1-\varepsilon) \rho_{\mathrm{s} 1} c_{\mathrm{s} 1} \frac{\partial T_{\mathrm{s} 1}}{\partial t}=\dot{Q}_{\mathrm{s} 1-\mathrm{f}}^{\prime \prime \prime} \quad \text { and } \\
& (1-w) \cdot(1-\varepsilon) \rho_{\mathrm{s} 2} c_{\mathrm{s} 2} \frac{\partial T_{\mathrm{s} 2}}{\partial t}=\dot{Q}_{\mathrm{s} 2-\mathrm{f}}^{\prime \prime \prime}
\end{aligned}
$$

The source terms $\dot{Q}_{\mathrm{f}-\mathrm{s} 1}^{\prime \prime \prime}$ and $\dot{Q}_{\mathrm{f}-\mathrm{s} 2}^{\prime \prime \prime}$ are calculated from equation (8). Equation (8) and the following equations are exemplarily given for the large particles $s 1$, the calculation for the small particles $s 2$ is analogous.

$$
\dot{Q}_{\mathrm{f}-\mathrm{s} 1}^{\prime \prime \prime}=-\dot{Q}_{\mathrm{s} 1-\mathrm{f}}^{\prime \prime \prime}=h_{\mathrm{vol}, 1} \cdot\left(T_{\mathrm{s} 1}-T_{\mathrm{f}}\right) .
$$

The lumped volumetric heat transfer coefficient for the $\mathrm{s} 1$ particles $h_{\mathrm{vol}, 1}$ is calculated from equation (9). This equation consists of the film coefficient $h_{\text {surf, } 1}$, the specific surface per volume $a_{\mathrm{v}, 1}$ and a second term for the thermal resistance through conduction in the particle (Schmidt and Willmott, 1981).

$$
h_{\mathrm{vol}, 1}=a_{\mathrm{v}, 1} \cdot\left(\frac{1}{h_{\mathrm{surf}, 1}}+\frac{5 \cdot d_{\mathrm{p} 1}}{2 \cdot \lambda_{\mathrm{s}}}\right)^{-1} .
$$

The specific surface per volume $a_{\mathrm{v}, 1}$ is calculated similarly to the monodisperse packings with the overall void fraction $\varepsilon$ but with the addition of the weighting factor $w$. For $a_{\mathrm{v}, 2}$, the basic equation is multiplied by $(1-w)$. Both equations thus read as followed:

$$
a_{\mathrm{v}, 1}=w \frac{6(1-\varepsilon)}{d_{\mathrm{p} 1}}, \quad a_{\mathrm{v}, 2}=(1-w) \frac{6(1-\varepsilon)}{d_{\mathrm{p} 2}} .
$$

The film heat transfer coefficient for the s1 particles $h_{\text {surf, } 1}$ is calculated by a widely used formula presented by (Wakao and Kagei, 1982), where $\operatorname{Pr}$ is the Prandtl number and Re the particle Reynolds number:

$$
h_{\mathrm{surf}, 1}=2+1.1 \cdot \operatorname{Pr}_{s 1}^{1 / 3} \cdot R e_{s 1}^{0.6} .
$$




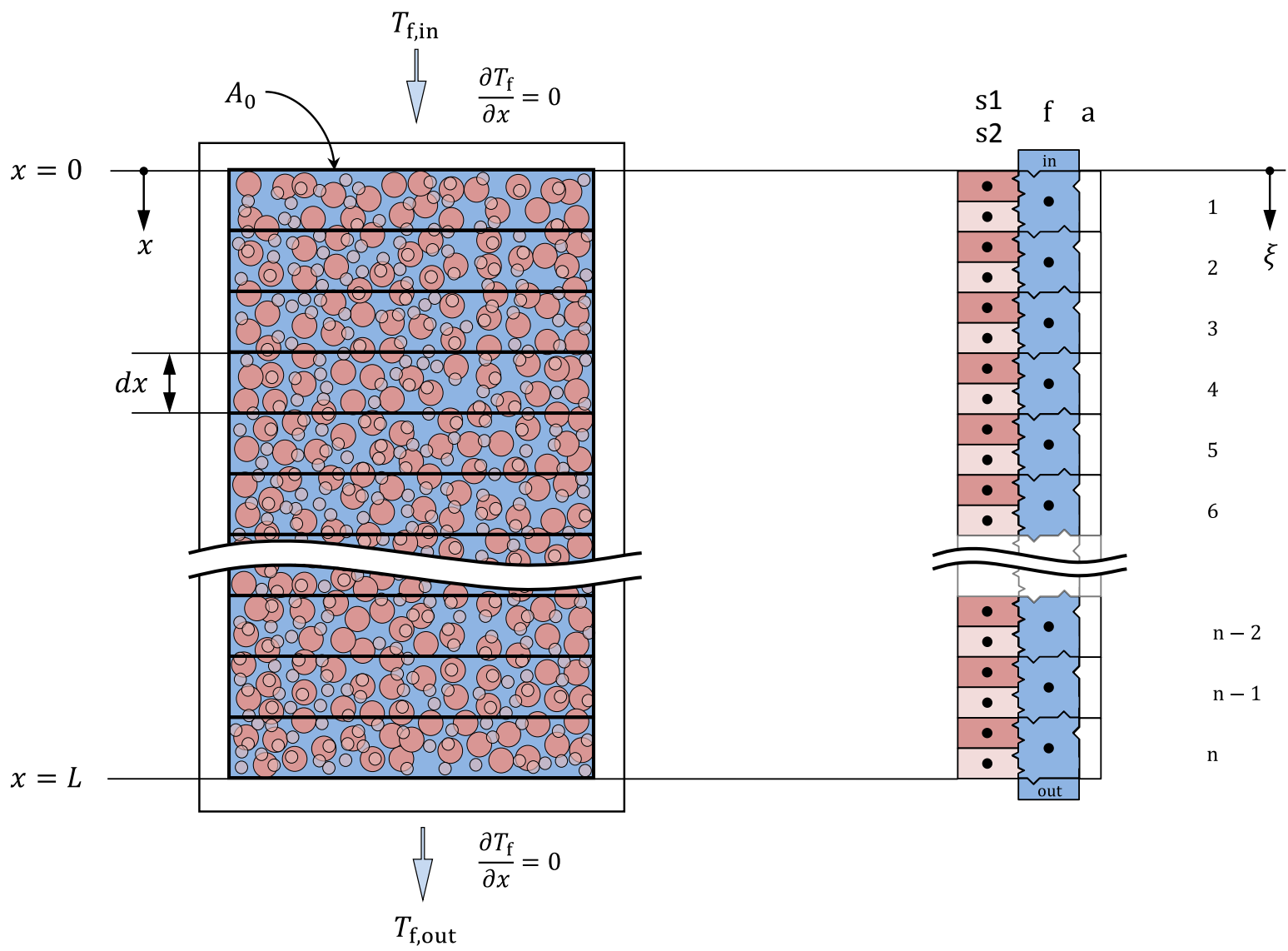

Fig. 5. Simplified representation and discretization scheme of the bidisperse model

\subsection{Numerical Implementation}

\section{Nondimensionalization of the equations}

239 The nondimensionalization of the equations is realized according to equation (12). For the

240 temperatures and time, a reference value $T_{\text {ref }}$ and $t_{\text {ref, }}$, respectively, are taken. The length is 241 nondimensionalized by the length $L$ of the storage volume.

$$
\Theta=\frac{T}{T_{\mathrm{ref}}}, \quad \tau=\frac{t}{t_{\mathrm{ref}}}, \quad \xi=\frac{x}{L} .
$$

\section{Discretization of the equations}

243 Transient discretization is done by a fully implicit scheme. At node $i$, the derivative with respect to 244 time reads

$$
\frac{\partial \Theta}{\partial t}=\frac{\Theta_{i}^{n+1}-\Theta_{i}^{n}}{\Delta \tau} .
$$

245 The convective derivative is discretized by a second order upwind scheme according to

$$
\frac{\partial \Theta}{\partial \xi}=\frac{\Theta_{i-2}^{n+1}-4 \Theta_{i-1}^{n+1}+3 \Theta_{i}^{n+1}}{2 \Delta \xi} .
$$


The boundary conditions of the PDEs must only be considered for the fluid temperatures and can be described as followed. In the inlet region, fluid temperatures at nodes outside the domain have a constant value of $\Theta_{\mathrm{f}, \text { in }}$

$$
\xi=0: \quad \Theta_{\mathrm{f},-2}=\Theta_{\mathrm{f},-1}=\Theta_{\mathrm{f}, \mathrm{in}} .
$$

In the outlet region, it is assumed that no heat flux is occurring, hence the outlet condition reads

$$
\xi=1: \quad \frac{\partial \Theta_{\mathrm{f}}}{\partial \xi}=0
$$

Initial conditions at $\tau=0$ are set up for both fluid and solid, according to equation (17). $\Theta_{\text {init }}$ is the nondimensionalized initial temperature.

$$
\tau=0: \quad \Theta_{\mathrm{f}, i}=\Theta_{\mathrm{s}, i}=\Theta_{\text {init }}
$$

\section{Implementation in MATLAB}

With above equations one yields a set of ordinary differential equations (ODEs), which leads to a system of linear dependent equations. They can be described by

$$
\left(\overline{\bar{I}}+\overline{\bar{M}}^{\mathbf{n}+1}\right) \cdot \Theta^{\mathbf{n}+1}=\Theta^{\mathbf{n}}+\boldsymbol{b} .
$$

$\overline{\overline{\boldsymbol{I}}}$ is the identity matrix, $\overline{\overline{\boldsymbol{M}}}^{\mathbf{n + 1}}$ a sparse band matrix, $\boldsymbol{\Theta}^{\mathbf{n + 1}}$ and $\boldsymbol{\Theta}^{\mathbf{n}}$ the vectors of the temperature field for the next and current time step, whilst vector $\boldsymbol{b}$ contains the boundary conditions. The linear system is solved by the Matlab ${ }^{\circledR}$ routine mldivide which is part of a DLR in-house tool for sizing regenerator type thermal energy storages.

\subsection{Model validation}

From the experimental data found in the literature, the data given by (Pacheco et al., 2002) appears most feasible for model validation, since it contains all nescessary information. Data is also available from (Hoffmann et al., 2016), however, only a monodisperse packing is used. The same applies to own experiments conducted by the authors (Odenthal et al., 2019). The data provided from the SolarOne experiments (Faas et al., 1986) lacks information about the filler size distribution. The data provided from the CEA experiments by (Bruch et al., 2014) is missing the information on the exact temperatures used during the experiments.

The simulation input data is summarized in Table 1. Information on initial temperature profiles and a comparison with the simulation is given in Fig. 6. For the validation, both the bidisperse and the Schumann model are used. To obtain the Schuman model from the bidisperse model, one of the solid equations is set to zero and for the other the mean particle diameter is used. As can be seen in Fig 5 (dashed and continuous line), both models yield nearly the same temperature profiles. Thus, it can be concluded that both models can depict the experimental results. Moreover, since the timespan covered by the validation simulation is rather short and practically no greater temperature differences occur, the results might lead to a false conclusion that there is no advantage of the bidisperse model over the monodisperse model. Therefore, in the next chapter a realistic scenario with larger time intervals is considered to investigate how differences between the Schumann and bidisperse model develop. 
Table 1: Bidisperse filler materials used in the literature and for the model validation

\begin{tabular}{lclll}
\hline Parameter & Symbol & Value & Unit \\
\hline Length of storage & $L$ & 6.1 & $\mathrm{~m}$ \\
Diameter of storage & $D$ & 3.0 & $\mathrm{~m}$ \\
Large particle diameter & $d_{\mathrm{p} 1}$ & 19.05 & $\mathrm{~mm}$ \\
Small particle diameter & $d_{\mathrm{p} 2}$ & 2.38 & $\mathrm{~mm}$ \\
Share of large filler & $w$ & 0.66 & - \\
Mean diameter & $d_{\mathrm{p}}$ & 13.38 & $\mathrm{~mm}$ \\
Void fraction & $\varepsilon$ & 0.22 & - \\
Large Filler material & - & Quartzite & - \\
Small Filler material & - & Sand & - \\
HTF & - & Solarsalt & - \\
Duration & $t_{\mathrm{sim}}$ & 3 & $\mathrm{~h}$ \\
Mass flow rate & $\dot{m}$ & 5.46 & $\mathrm{~kg} / \mathrm{s}$ \\
Inlet temperature & $T_{\mathrm{in}}$ & 289.0 & ${ }^{\circ} \mathrm{C}$ \\
grid size & $\Delta x$ & 1 & $\mathrm{~cm}$ \\
Time step length & $\Delta t$ & 5 & $\mathrm{~s}$ \\
\hline
\end{tabular}

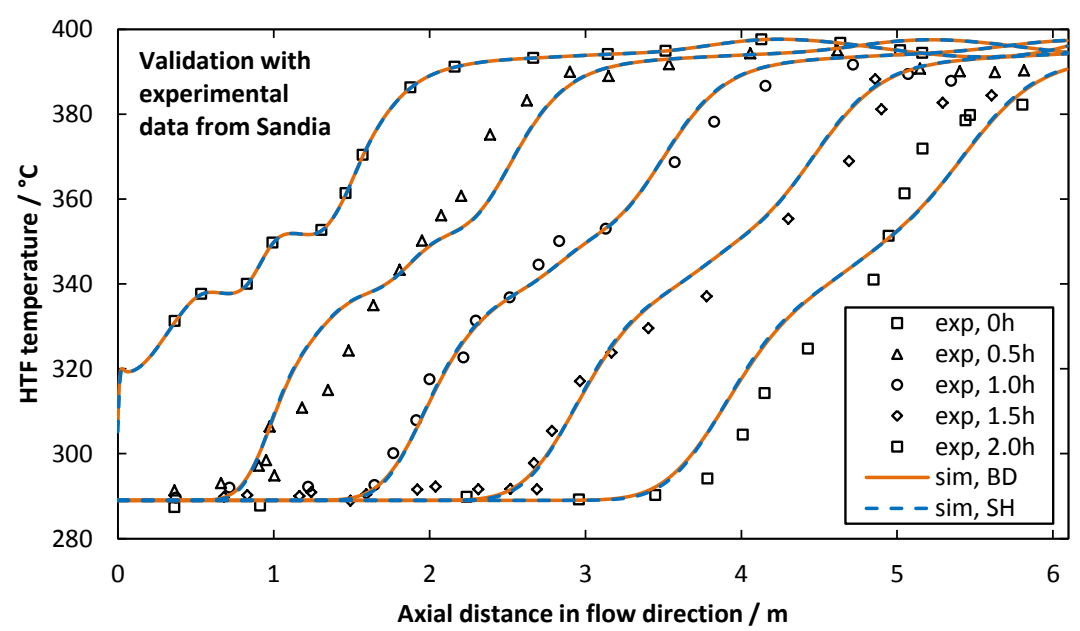

Fig. 6: Validation of the two models with experimental data from (Pacheco et al., 2002). Simulations were run with the Schumann model (SH) and the bidisperse model (BD).

\section{Investigated scenarios}

\subsection{General case of application}

For the present study, a solar thermal power plant using Solar Salt as heat transfer fluid (HTF) is considered. The plant has a nominal thermal power of $235 \mathrm{MW}_{\text {th }}$, which equals an electric power of $100 \mathrm{MW}_{\mathrm{el}}$. The inlet temperature is $550^{\circ} \mathrm{C}$ and the outlet temperature $310^{\circ} \mathrm{C}$, the necessary mass flow rate of Solar Salt is $630 \mathrm{~kg} / \mathrm{s}$.

In terms of the storage size, it is assumed that in a cyclic steady state, i.e. after several consecutive charging and discharging cycles with above inlet conditions, the storage can be charged for 12 hours with a maximum temperature change at the outlet of 40 Kelvin. Furthermore, the height of the storage volume is assumed to be 10 meters. Typical values for two-tank storage systems are in the range of 1214 m (González-Roubaud et al., 2017). 
For the filler material a certain range should be covered, as illustrated by Fig. 7. Four different filler $2 \mathrm{~mm}$ particles which typically would yield a void fraction of $40 \%$. On the other end of the range, we assume a bidisperse packing of small particles with $2 \mathrm{~mm}$ in diameter and large particles with $50 \mathrm{~mm}$ diameter. The void fraction assumed is $22 \%$ in conjunction with values given in the literature (Faas et al., 1986; Hoffmann et al., 2016; Pacheco et al., 2002). Furthermore, two intermediate particle configurations are assumed (see Table 2). For all bidisperse packings, a share of $70 \%$ for the larger particles is assumed, as a typical value (Yu et al., 1996). As also illustrated in Fig. 7, there are certain ranges within the different types of models discussed in the introduction might be suitable. The given boundaries are arbitrary and for illustrational purpose. In fact the present work should provide help in deciding which model is suitable for a given application. The single phase model should yield inaccurate results as particle sizes are increasing and the assumption of infinite heat transfer is not valid any more. For the Schuman model, the assumption of a mean diameter should also lead to increasing inaccuracy of the simulation with increasing particle size differences of small and large particles. From this point on, the bidisperse model should be more accurate. Albeit Schumann and bidisperse model can cover the whole range, those models using fewer differential equations might be a better choice in terms of computing effort.

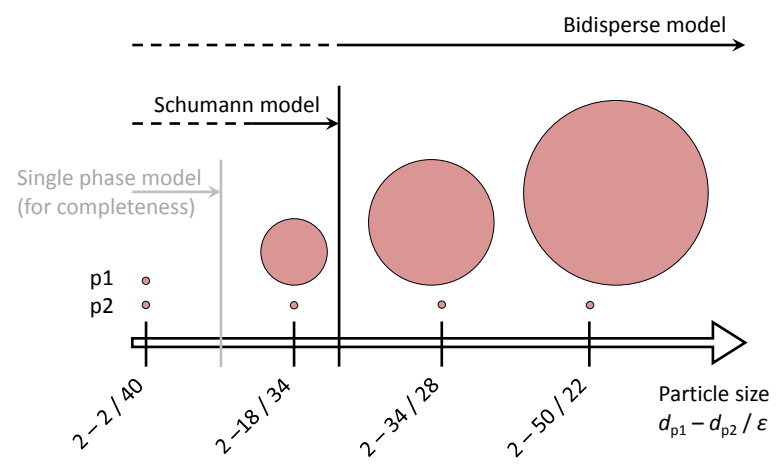

Fig. 7: Overview of investigated particle size distributions and suitable models for the investigation. Single phase model is shown for completeness and is not part of the presented modeling work.

With above assumptions and specifications, the actual storage dimensions can be determined. The storage is simulated in cyclic operation with the given permitted change in exit temperature as criterion for switching the operation mode of charging and discharging. The simulations are repeated until cyclic steady state is reached. A simplex algorithm is used to adjust the cross sectional area in a way, that the predefined charging time of 12 hours is reached. Sizing simulations were run with the 2$2 / .40$ and the 2-50/.22 particle sizes and an average cross section area from both simulations of $1700 \mathrm{~m}^{2}$ was taken. The resulting dimensions are summarized in the last section of Table 2. 
Table 2: Summary of boundary conditions, storage specifications and operating parameters

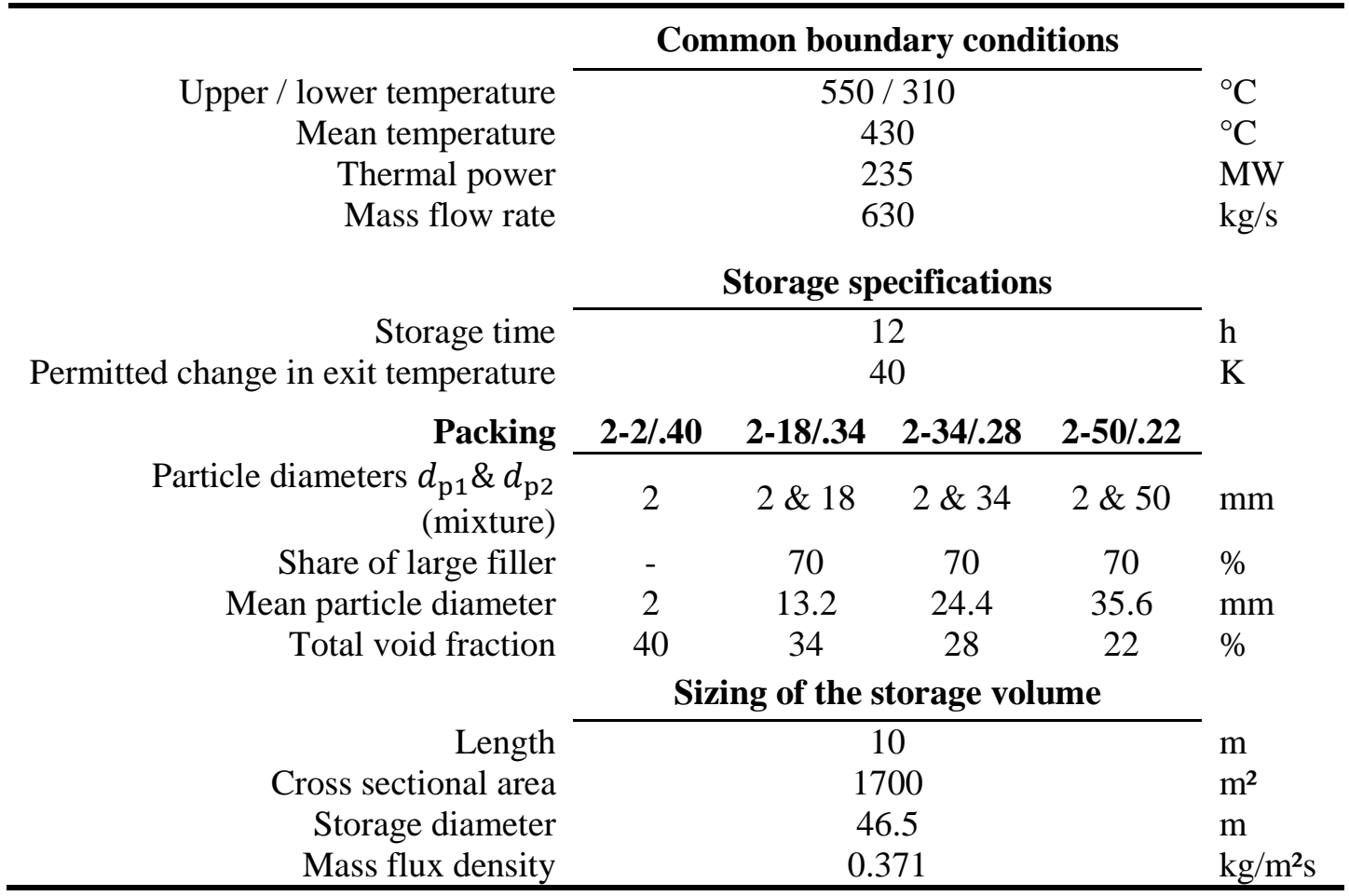

\subsection{Outer boundary conditions and evaluation}

For the investigation of the bidisperse model, the four different packings are simulated for 14 consecutive cycles, where one cycle consists of a charging and a discharging period with the inlet conditions given in Table 2. Simulations are run both with the bidisperse model (BD) and with the Schuman model $(\mathrm{SH})$. For the Schumann model the mean particle diameters are used, which are also given by Table 2 .

\section{Single blow operation}

To assess the differences between the models, two cases are considered. The first one is the difference after 6 hours of the initial charging period, which is often referred to as the single blow operation. For this case, the mean temperature difference $\Delta \bar{T}_{\mathrm{f}}$ between the temperature curve of the bidisperse model and the Schumann model are calculated. To calculate $\Delta \bar{T}_{\mathrm{f}}$, the absolute differences at each fluid node $i$ are taken and divided by the total number of nodes $n$.

$$
\Delta \bar{T}_{\mathrm{f}}=\frac{1}{n} \sum_{i}\left|T_{\mathrm{f}, i}^{\mathrm{BD}}-T_{\mathrm{f}, i}^{\mathrm{SH}}\right|
$$

Furthermore, the maximum occurring temperature difference $\Delta T_{\mathrm{f}, \max }$ between the $\mathrm{SH}$ and the $\mathrm{BD}$ model are calculated from

$$
\Delta T_{\mathrm{f}, \max }=\max \left|T_{\mathrm{f}, i}^{\mathrm{BD}}-T_{\mathrm{f}, i}^{\mathrm{SH}}\right|
$$

\section{Cyclic operation}

The second case is the difference between SH and BD modeling results after the cyclic operation. In that case, temperature differences would not be expedient, since the positions of the temperature curves differ among the results. Instead, the total time for the last discharging period $\Delta t_{\text {per }}^{\prime \prime}$ as well as the total simulation time $\Delta \mathrm{t}_{\text {sim }}$ are compared to the Schumann model $(\mathrm{SH})$. This approach allows a better comparison to clarify differences of the model outcome in the long term. 


\section{Comparison of the bidisperse model to the Schumann modeling results}

In a first step a grid study is performed, to ensure consistent results. Results of the single blow simulation are compared with variations of grid size and time step length. Simulations were run with the 2-2/.40 packing, since gradients are highest here. In a first step, grid spacing is set to $0.05 \mathrm{~cm}$ and simulations with a time step length of 0.02 seconds is taken as reference. For a time step of 2 seconds, the mean deviation $\Delta \bar{T}_{\mathrm{f}}$ is 0.08 Kelvin, which is below the threshold of $0.1 \mathrm{Kelvin}$. In a second step, the time step is kept at 2 seconds and the grid size of $0.05 \mathrm{~cm}$ is taken as reference. Due to the strong gradients, some numerical instability occurred, if grid size was extended. Thus, all simulations are run with $0.05 \mathrm{~cm}$ grid size.

\subsection{Single blow operation}

The results of the single blow operation for the four investigated packings defined in Table 2 are shown in Fig. 8. The plots show the spatial temperature profiles in axial flow direction. A magnification is given for better readability of the values. For the $2 \mathrm{~mm}$ particles, the Schumann and bidisperse model yield the same temperature curves, since there is no difference in particle sizes. With increasing size difference of the particles, results between both models differ increasingly. Accompanied with this, the thermocline thickness is also increasing with larger particles. The reason for this is that they are limiting the heat transfer due to their smaller total heat transferring surface and larger conductive resistance into the particles. Thus, the section where heat transfer takes place, i.e. thermocline region, is increasing as well. For the 2-18/.34 packing, the maximum temperature difference between both models $\Delta T_{\mathrm{f}, \max }$ is 5 Kelvin, which further grows up to 6.6 Kelvin for the 2$50 / .22$ packing. The mean temperature difference $\Delta \bar{T}_{\mathrm{f}}$ reaches a value of almost 1 Kelvin. The exact values for mean temperature difference $\Delta \bar{T}_{\mathrm{f}}$ and maximum temperature difference $\Delta T_{\mathrm{f} \text { max }}$ are also summarized in Table 3. Contrary to the validation simulation (see Fig. 6), where the packing was similar to the 2-18/.34 packing, the visible temperature differences are more distinct due to the strong gradient occurring in the first seconds of operation. For the larger particles, the differences become clearly visible in the plotted graphs.
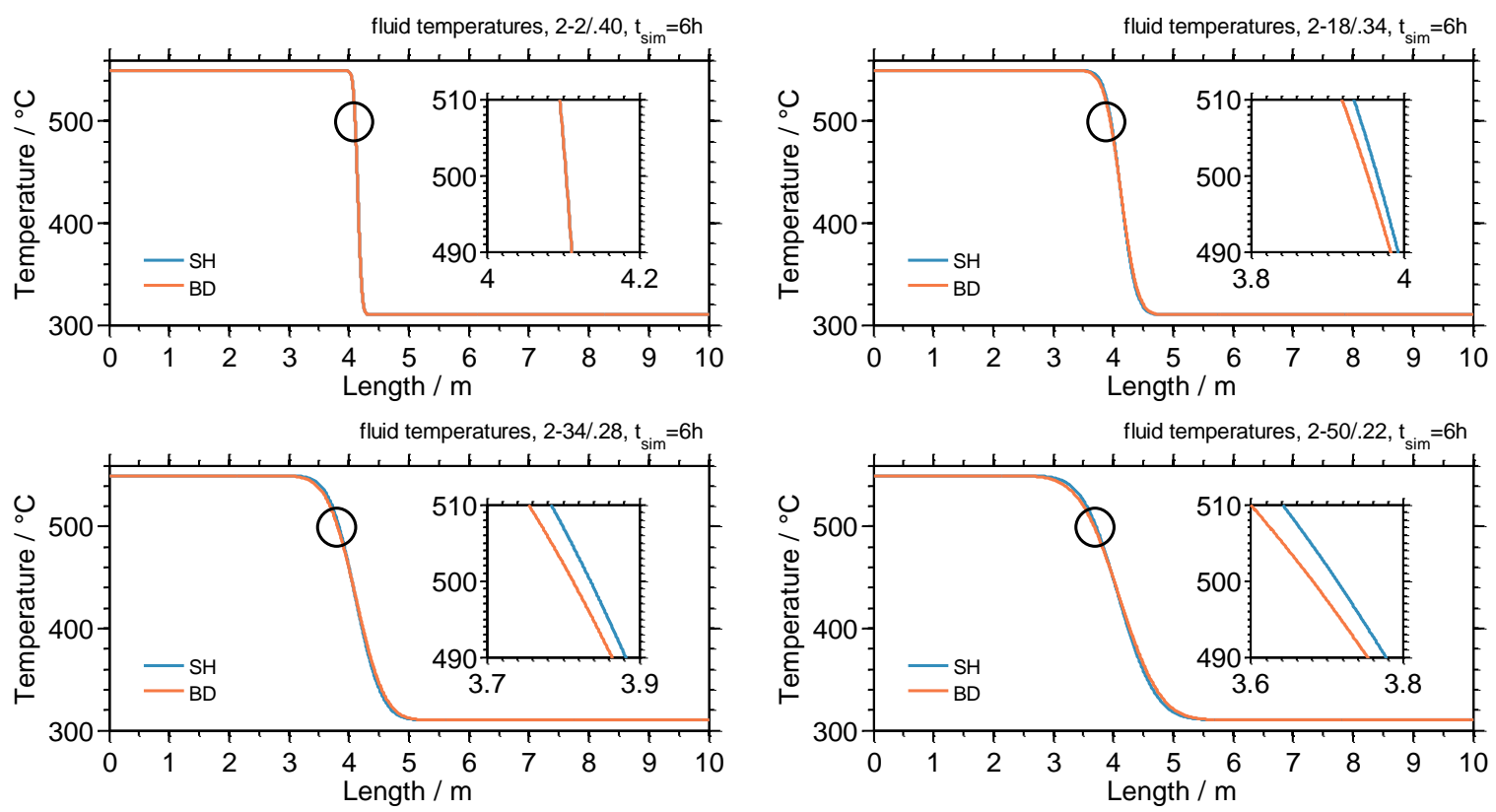

Fig. 8: Fluid temperature curves in flow direction of the Schumann and bidisperse model after 6 hours of operation for a variation of particle sizes, starting from only $2 \mathrm{~mm}$ particles up to $2 \& 50 \mathrm{~mm}$ particles.

Compared to the single blow discussion in this section, the next section deals with the outcome after several consecutive cycles. 
Fig. 9 shows the fluid temperature profiles in flow direction at the beginning of the last discharge period of the $14^{\text {th }}$ cycle. For the $2-2 / .40$ packing, the bidisperse model expectedly equals the SH model again. It can be seen that the deviation increases with increasing difference of the particle diameters. Further analysis shows that there is a linear trend of the deviations. With the next larger particle size 2$18 / .34$, the mean temperature difference $\Delta \bar{T}_{\mathrm{f}}$ is now 1.3 Kelvin and the maximum $\Delta T_{\mathrm{f} \text {,max }}$ already 11.5 Kelvin. These differences further grow and eventually reach 3 Kelvin mean temperature difference $\Delta \bar{T}_{\mathrm{f}}$ and 12.4 Kelvin maximum temperature difference $\Delta T_{\mathrm{f} \text {,max }}$ for the 2-50/.22 packing. All values are also summarized in Table 3.
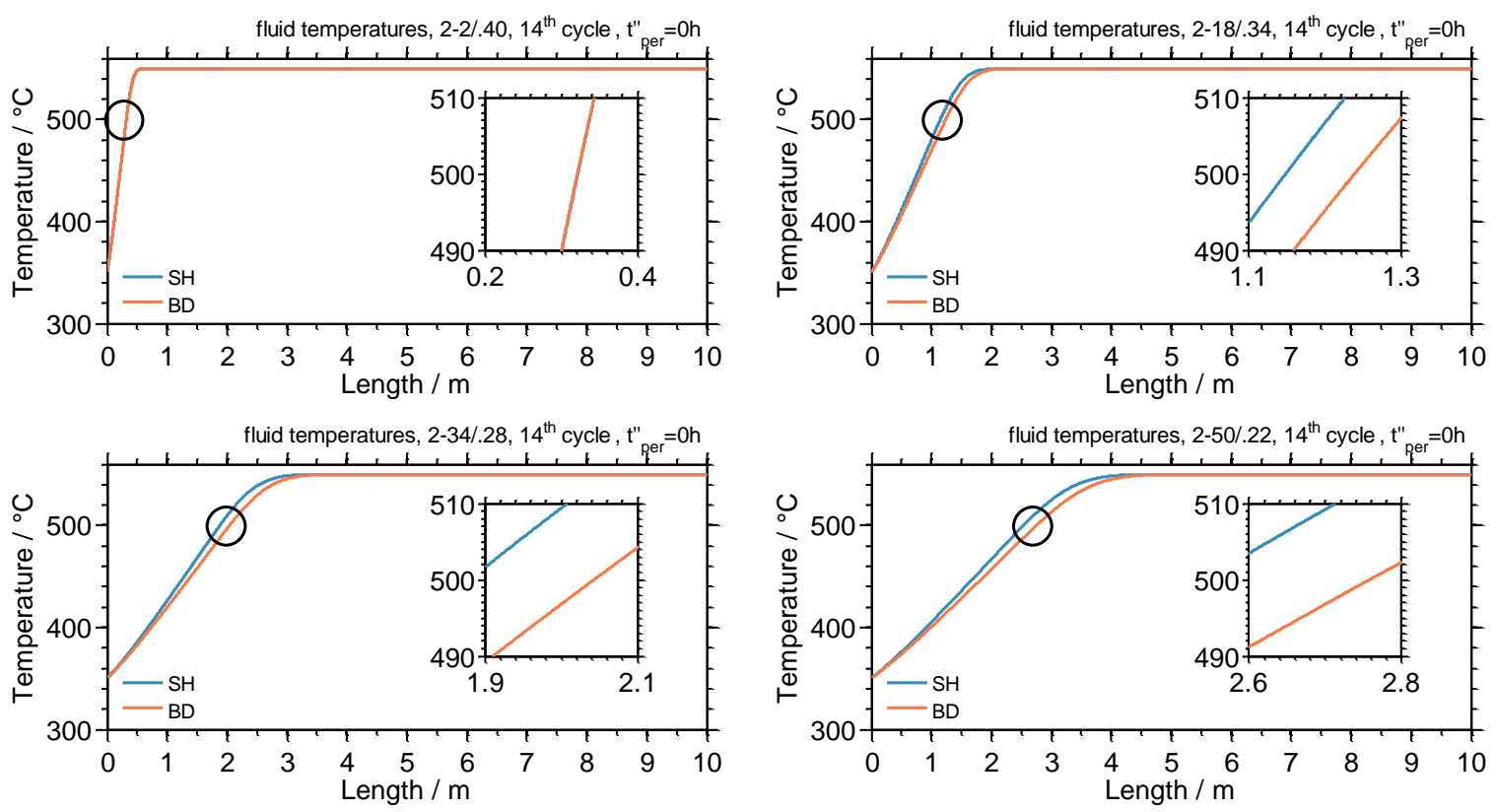

397

398

399

400

401

402

403

404

405

406

407

408

409

410

411

412

413

414

415

416

Fig. 9: Fluid temperature curves in flow direction of the Schumann and bidisperse model at the beginning of the last discharge period (after 14 cycles) for a variation of particle sizes, starting from only $2 \mathrm{~mm}$ particles up to $2 \& 50 \mathrm{~mm}$ particles.

The differences between the two models can also expressed in a different way by looking at the deviations in the duration of the last discharge period $\Delta t_{\text {per }}^{\prime \prime}$ or the total simulation time $\Delta \mathrm{t}_{\text {sim }}$, which are also shown in Table 3. Also given in Table 3 are the differences between the models expressed in percent. For the 2-18/.34 packing, the last discharge period is 9 mins or $1.2 \%$ shorter with the bidisperse model compared to the Schumann model. The total simulation time is almost 4 hours shorter, which is around $1 \%$. With the largest packing 2-50/.22, the difference between Schumann and bidisperse model is 23 mins or $3.6 \%$ shorter in the duration of the last discharge period and 9.5 hours or $3.2 \%$ for the simulation time. Expressed this way, the differences both in the length of the last period and simulation time increase almost linearly. 

packings in terms of temperature differences for the single blow operation and in terms of simulation time for the cyclic operation.

\begin{tabular}{|c|c|c|c|c|c|c|c|c|c|}
\hline \multirow{3}{*}{$\begin{array}{l}\text { Packing } \\
\text { (particle size / } \\
\text { void fraction) }\end{array}$} & \multicolumn{2}{|c|}{$2-2 / .40$} & \multicolumn{2}{|c|}{$2-18 / .34$} & \multicolumn{2}{|c|}{$2-34 / .28$} & \multicolumn{2}{|c|}{$2-50 / .22$} & \\
\hline & \multicolumn{9}{|c|}{ Single blow operation } \\
\hline & $\Delta \overline{T_{\mathrm{f}}}$ & $\Delta T_{\mathrm{f}, \max }$ & $\Delta \overline{T_{\mathrm{f}}}$ & $\Delta T_{f, \max }$ & $\Delta \overline{T_{\mathrm{f}}}$ & $\Delta T_{\mathrm{f}, \max }$ & $\Delta \overline{T_{\mathrm{f}}}$ & $\Delta T_{\mathrm{f}, \max }$ & \\
\hline \multirow[t]{2}{*}{ difference (abs) } & 0.00 & 0.00 & 0.33 & 5.00 & 0.65 & 6.03 & 0.97 & 6.58 & $\mathrm{~K}$ \\
\hline & \multicolumn{8}{|c|}{ Cyclic operation } & \\
\hline \multirow[t]{2}{*}{ difference (abs) } & 0.00 & 0.00 & 1.26 & 11.51 & 2.28 & 12.59 & 3.03 & 12.41 & $\mathrm{~K}$ \\
\hline & $\Delta t_{\text {per }}^{\prime \prime}$ & $\Delta t_{\text {sim }}$ & $\Delta t_{\text {per }}^{\prime \prime}$ & $\Delta \mathbf{t}_{\text {sim }}$ & $\Delta t_{\text {per }}^{\prime \prime}$ & $\Delta \mathbf{t}_{\text {sim }}$ & $\Delta t_{\text {per }}^{\prime \prime}$ & $\Delta \mathbf{t}_{\text {sim }}$ & \\
\hline difference (abs) & 0.0 & 0.0 & 9.0 & 222.2 & 16.6 & 413.3 & 22.6 & 571.5 & $\min$ \\
\hline difference (rel) & 0.00 & 0.00 & 1.18 & 1.07 & 2.39 & 2.16 & 3.59 & 3.25 & $\%$ \\
\hline
\end{tabular}

\section{Conclusion}

In this work, a novel bidisperse model (BD) has been introduced, using two partial differential equations for the solid phase. The model has been validated with experimental data and showed similar agreement as the often used Schumann model (SH). Subsequently, a reference case was defined and used for further investigations. Simulations of the single blow behavior and of several consecutive cycles showed increasing differences with increasing size ratio of the large and small particles for bidisperse packings. For the largest investigated ratio of $2 \mathrm{~mm} \& 50 \mathrm{~mm}$ particles, the temperature curves differed up to 6.6 Kelvin after 6 hours of simulation. After 14 consecutive cycles, the duration of the last discharge period was 22.6 minutes or $3.6 \%$ shorter with the BD model compared to the SH model. The maximum temperature difference at the beginning of the last discharge cycle was more than 12 Kelvin. The investigation showed that although there was only little difference between SH and BD model during the validation simulation, the simulation of consecutive cyclic operation led to a significant difference in the model outcome.

The improvement achieved by introducing the bidisperse model appears to be in the same order of magnitude as the consideration of other effects such as variable fluid properties, heat losses or effective conductivity. Particularly the latter effect is considered by most authors in the continuous solid phase model as described in the introduction. Hence, it is suggested to use a bidisperse model as described in this work, if packed beds with two distinct particle sizes for thermocline TES with fluids such as oil or molten salt are simulated. The results indicated that with increasing number of cycles, differences between the two models increase further. The observed differences are not quite apparent after short simulation times such as model validations or single blow operation. Thus, investigating the model outcome over longer time periods is always recommended.

\section{Acknowledgements}

The authors thank the German Federal Ministry for Economic Affairs and Energy for the financial support given for this work in the MS-STORE project (Contract No. 0325497 A).

\section{Nomenclature}

Symbols

$a_{\mathrm{v}}$
$A_{0}$
$c, c_{\mathrm{p}}$

specific surface per volume

$\left(\mathrm{m}^{2} / \mathrm{m}^{3}\right)$

storage cross sectional area $\quad\left(\mathrm{m}^{2}\right)$

specific heat capacity

$(\mathrm{J} / \mathrm{kgK})$ 


$\begin{array}{llll}450 & d_{\mathrm{p}} & \text { particle diameter } & (\mathrm{m}) \\ 451 & D & \text { storage diameter } & (\mathrm{m}) \\ 452 & h & \text { specific enthalpy } & (\mathrm{J} / \mathrm{kg}) \\ 453 & h_{\text {surf }} & \text { surface film heat transfer coeff. }\left(\mathrm{W} / \mathrm{m}^{2}\right) \\ 454 & h_{\text {vol }} & \text { volumetric heat transfer coeff. } & \left(\mathrm{W} / \mathrm{m}^{3}\right) \\ 455 & L & \text { storage length } & (\mathrm{m}) \\ 456 & \dot{m} & \text { mass flow } & (\mathrm{kg} / \mathrm{s}) \\ 457 & n & \text { number of nodes } & (-) \\ 458 & p & \text { pressure } & (\mathrm{Pa}) \\ 459 & P & \text { work } & (\mathrm{W}) \\ 460 & P r & \text { Prandtl number } \mu c_{\mathrm{p}} / \lambda & (-) \\ 461 & P e & \text { Péclet number } R e \cdot P r & (-) \\ 462 & Q^{\prime \prime \prime} & \text { volumetric heat source/sink } & \left(\mathrm{W} / \mathrm{m}^{3}\right) \\ 463 & R e & \text { Reynolds number } \dot{m} d_{\mathrm{p}} / A_{0} \lambda \mu & (-) \\ 464 & t & \text { time } & (\mathrm{s}) \\ 465 & \Delta \bar{T}_{\mathrm{f}} & \text { mean fluid temp. diff. } & (\mathrm{K}) \\ 466 & \Delta T_{\mathrm{f}, \mathrm{max}} & \text { max. fluid temp. diff. } & (\mathrm{K}) \\ 467 & V_{\mathrm{p}} & \text { particle volume } & \left(\mathrm{m}^{3}\right) \\ 468 & u & \text { specific inner energy } & (\mathrm{J} / \mathrm{kgK}) \\ 469 & v_{0} & \text { free flow velocity } & (\mathrm{m} / \mathrm{s}) \\ 470 & w & \text { weighting factor } & (-) \\ 471 & x & \text { axial coordinate } & (\mathrm{m})\end{array}$

472

473

474

475

476

477

478

479

480

481

482

483

484

485

486

487

488

489

490

491

492

493

494

495

496

497

498 difference

void fraction

dimensionless distance

thermal conductivity

dynamic viscosity

density

dimensionless time

dimensionless temperature
$(-)$

$(-)$

$(-)$

(W/mK)

(Pa s)

$\left(\mathrm{kg} / \mathrm{m}^{3}\right)$

$(-)$

$(-)$

\section{Subscripts}

eff

$\mathrm{f}$

i

init

$\max , \min$

per

$\mathrm{p}, \mathrm{p} 1, \mathrm{p} 2$

ref

sim

$\mathrm{s}$

s1, s2

$\mathrm{x}$

effective value

fluid

node $\mathrm{i}$

initial condition

maximum, minimum

period

particle, particle 1 , particle 2

reference

simulation

solid

solid 1, solid 2

position in flow direction

\section{Superscripts}

$\begin{array}{ll}\mathrm{n} & \text { time step } \mathrm{n} \\ ، & \text { charging period } \\ & \text { discharging period }\end{array}$




\section{References}

Bayón, R., Rojas, E., 2013. Simulation of thermocline storage for solar thermal power plants: From dimensionless results to prototypes and real-size tanks. International Journal of Heat and Mass Transfer 60, 713-721. https://doi.org/10.1016/j.ijheatmasstransfer.2013.01.047

Brosseau, D. a, Hlava, P.F., Kelly, M.J., 2005. Testing Thermocline Filler Materials and Molten - Salt Heat Transfer Fluids for Thermal Energy Storage Systems Used in Parabolic Trough Solar Power Plants. https://doi.org/10.1115/ISEC2004-65144

Bruch, A., Fourmigué, J.F., Couturier, R., 2014. Experimental and numerical investigation of a pilotscale thermal oil packed bed thermal storage system for CSP power plant. Solar Energy 105, 116-125. https://doi.org/10.1016/j.solener.2014.03.019

Esence, T., Bruch, A., Molina, S., Stutz, B., Fourmigué, J.F., 2017. A review on experience feedback and numerical modeling of packed-bed thermal energy storage systems. Solar Energy 153, 628-654. https://doi.org/10.1016/j.solener.2017.03.032

Faas, S.E., Thorne, L.R., Fuchs, E.A., Gilbertsen, N.D., 1986. 10 MWe Solar Thermal Central Receiver Pilot Plant: Thermal Storage Subsystem Evaluation Final report.

Fasquelle, T., Falcoz, Q., Neveu, P., Lecat, F., Boullet, N., Flamant, G., 2017. Operating results of a thermocline thermal energy storage included in a parabolic trough mini power plant. AIP Conference Proceedings 1850. https://doi.org/10.1063/1.4984431

Flueckiger, S.M., Iverson, B.D., Garimella, S.V., Pacheco, J.E., 2014. System-level simulation of a solar power tower plant with thermocline thermal energy storage. Applied Energy 113, 86-96. https://doi.org/10.1016/j.apenergy.2013.07.004

Galione, P.A., Pérez-Segarra, C.D., Rodríguez, I., Torras, S., Rigola, J., 2015. Multi-layered solidPCM thermocline thermal storage for CSP. Numerical evaluation of its application in a 50MWe plant. Solar Energy 119, 134-150. https://doi.org/10.1016/j.solener.2015.06.029

Gil, A., Medrano, M., Martorell, I., Lázaro, A., Dolado, P., Zalba, B., Cabeza, L.F., 2010. State of the art on high temperature thermal energy storage for power generation. Part 1--Concepts, materials and modellization. Renewable and Sustainable Energy Reviews 14, 31-55. https://doi.org/10.1016/j.rser.2009.07.035

González-Roubaud, E., Pérez-Osorio, D., Prieto, C., 2017. Review of commercial thermal energy storage in concentrated solar power plants: Steam vs. molten salts. Renewable and Sustainable Energy Reviews 80, 133-148. https://doi.org/10.1016/j.rser.2017.05.084

Herrmann, U., Kelly, B., Price, H., 2004. Two-tank molten salt storage for parabolic trough solar power plants. Energy 29, 883-893. https://doi.org/10.1016/S0360-5442(03)00193-2

Hoffmann, J.-F., Fasquelle, T., Goetz, V., Py, X., 2017. Experimental and numerical investigation of a thermocline thermal energy storage tank. Applied Thermal Engineering 114, 896-904. https://doi.org/10.1016/j.applthermaleng.2016.12.053

Hoffmann, J.-F., Fasquelle, T., Goetz, V., Py, X., 2016. A thermocline thermal energy storage system with filler materials for concentrated solar power plants: Experimental data and numerical model sensitivity to different experimental tank scales. Applied Thermal Engineering 100, 753-761. https://doi.org/10.1016/j.applthermaleng.2016.01.110

Ismail, K. a. R., Stuginsky Jr, R., 1999. A parametric study on possible fixed bed models for pcm and sensible heat storage. Applied Thermal Engineering 19, 757-788. https://doi.org/10.1016/S1359-4311(98)00081-7

Kays, W.M., Crawford, M.E., Weigand, B., 2009. Convective heat and mass transfer, 4. ed., McGrawHill internat. ed., [Nachdr.]. ed, McGraw-Hill series in mechanical engineering. McGraw-Hill, Boston.

Kunii, D., Smith, J.M., 1960. Heat transfer characteristics of porous rocks. AIChE J. 6, 71-78. https://doi.org/10.1002/aic.690060115 
Li, P., Van Lew, J., Karaki, W., Chan, C., Stephens, J., Wang, Q., 2011. Generalized charts of energy storage effectiveness for thermocline heat storage tank design and calibration. Solar Energy 85, 2130-2143. https://doi.org/10.1016/j.solener.2011.05.022

Niedermeier, K., Marocco, L., Flesch, J., Mohan, G., Coventry, J., Wetzel, T., 2018. Performance of molten sodium vs. molten salts in a packed bed thermal energy storage. Applied Thermal Engineering 141, 368-377. https://doi.org/10.1016/j.applthermaleng.2018.05.080

Odenthal, C., Klasing, F., Bauer, T., 2019. First Experimental Results of World's Largest HighTemperature Molten Salt Thermocline Storage System with Filler, in: IRES 2019. Presented at the International Renewable Energy Storage Conference, Düsseldorf.

Olaf Winter, 2019. Wegweisendes Pilotprojekt: Im Rheinischen Revier entsteht ein Wärmespeicherkraftwerk. URL https://news.rwe.com/wegweisendes-pilotprojekt-imrheinischen-revier-entsteht-ein-warmespeicherkraftwerk/

Pacheco, J.E., Showalter, S.K., Kolb, W.J., 2002. Development of a Molten-Salt Thermocline Thermal Storage System for Parabolic Trough Plants. Journal of Solar Energy Engineering 124, 153. https://doi.org/10.1115/1.1464123

Reddy, K.S., Jawahar, V., Sivakumar, S., Mallick, T.K., 2017. Performance investigation of singletank thermocline storage systems for CSP plants. Solar Energy 144, 740-749. https://doi.org/10.1016/j.solener.2017.02.012

Rhodes, M.J., 2008. Introduction to particle technology, 2nd ed. ed. Wiley, Chichester, England; Hoboken, NJ.

Rodat, S., Bavière, R., Bruch, A., Camus, A., 2018. Dynamic simulation of a Fresnel solar power plant prototype with thermocline thermal energy storage. Applied Thermal Engineering 135, 483492. https://doi.org/10.1016/j.applthermaleng.2018.02.083

Rodat, S., Bruch, A., Dupassieux, N., Mourchid, N. El, 2015. Unique Fresnel Demonstrator Including ORC and Thermocline Direct Thermal Storage: Operating Experience. Energy Procedia 69, 1667-1675. https://doi.org/10.1016/j.egypro.2015.03.127

Schmidt, F.W., Willmott, A.J., 1981. Thermal energy storage and regeneration, 1st ed. Hemisphere Publishing Corporation, Washington, D.C., USA.

Schumann, T.E.W., 1929. Heat transfer: A liquid flowing through a porous prism. Journal of the Franklin Institute 208, 405-416. https://doi.org/10.1016/S0016-0032(29)91186-8

Valmiki, M.M., Karaki, W., Li, P., Lew, J.V., Chan, C., Stephens, J., 2012. Experimental Investigation of Thermal Storage Processes in a Thermocline Tank. Journal of Solar Energy Engineering 134, 041003. https://doi.org/10.1115/1.4006962

Van Lew, J.T., Li, P., Chan, C.L., Karaki, W., Stephens, J., 2009. Transient Heat Delivery and Storage Process in a Thermocline Heat Storage System 139-148. https://doi.org/10.1115/IMECE200911701

Wakao, N., Kagei, S., 1982. Heat and mass transfer in packed beds. Gordon and Breach Science Publishers Inc., New York.

Willmott, A., 2002. Dynamics of regenerative heat transfer, 1st ed. Taylor \& Francis, London.

Yang, Xiaoping, Yang, Xiaoxi, Ding, J., Shao, Y., Qin, F.G.F., Jiang, R., 2012. Criteria for performance improvement of a molten salt thermocline storage system. Applied Thermal Engineering 48, 24-31. https://doi.org/10.1016/j.applthermaleng.2012.04.046

Yu, A.B., Zou, R.P., Standish, N., 1996. Modifying the linear packing model for predicting the porosity of nonspherical particle mixtures. Industrial and Engineering Chemistry Research 35, 3730-3741. https://doi.org/10.1021/ie950616a

Zhao, B., Cheng, M., Liu, C., Dai, Z., 2017. An efficient tank size estimation strategy for packed-bed thermocline thermal energy storage systems for concentrated solar power. Solar Energy 153, 104-114. https://doi.org/10.1016/j.solener.2017.05.057 